Maden, A. (2020). Akıcı okuma ile ilgili lisansüstü tezlerin araştırma eğilimleri: Bir betimsel analiz çalışması. Ana Dili Eğitimi Dergisi, 8(2), 543-558.

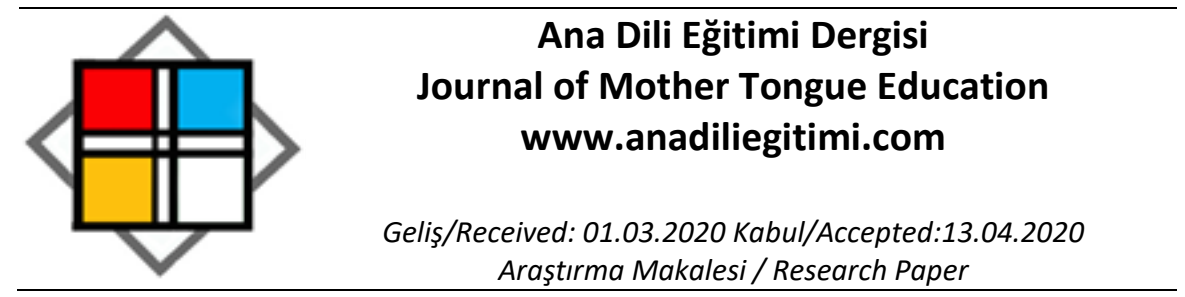

\title{
Akıcı Okuma ile İlgili Lisansüstü Tezlerin Araştırma Eğilimleri: Bir Betimsel Analiz Çalışması
}

\author{
Aslı MADEN*
}

Öz

Araştırmada akıcı okuma ile ilgili lisansüstü tezlerin tespit edilmesi ve çeşitli açılardan analiz edilerek eğilimlerinin ortaya konulması amaçlanmıştır. Araştırmada betimsel içerik analizi yöntemi uygulanmıştır. Araştırmanın veri kaynağını, Yükseköğretim Kurulu (YÖK) Ulusal Tez Merkezinde yer alan akıcı okuma üzerine, 2020 yılına kadar, hazırlanmış olan lisansüstü tezler oluşturmaktadır. Veri kaynağını oluşturan tezler, Ulusal Tez Merkezi genel ağ sayfası taranarak tespit edilmiştir. Araştırmada, yayın sınıflama formu kullanılmıştır. Araştırma sonucunda, akıcı okuma ile ilgili 2009 yılından bu yana 43 farklı tezin hazırlandığı tespit edilmiştir. Akıcı okumayla ilgili en fazla 2019 yılında tez yazıldığı, bu tezlerin daha çok Gazi Üniversitesi'nin lisansüstü programlarında hazırlandığı görülmüştür. Bununla birlikte akıcı okumaya dair tezlerde daha çok akıcı okuma becerisini geliştirme konusunun tercih edildiği belirlenmiştir. Ayrıca ulaşılan sonuçlar akıcı okumaya yönelik tezlerde nicel araştırma desenlerine ve bu desenlere bağlı olarak ise ölçek, test, envanter gibi araçların kullanılmasına dair bir eğilimin olduğunu göstermektedir.

Anahtar Kelimeler: Okuma, akıcı okuma, tez, eğilim, betimsel analiz.

\section{The Research Trends of Postgraduate Theses on Fluent Reading: A Descriptive Analysis Study}

\begin{abstract}
In the study, it is aimed to determine the tendencies of graduate theses related to fluent reading. The research was carried out according to descriptive content analysis method was used. The data source of the research consists of postgraduate theses on fluent reading in the Council of Higher Education National Thesis Center, prepared until the 2020. The data source of the research was created by scanning through the National Thesis Center website. In the study publication classification form was used. The form has been arranged in accordance with the purpose and content of the study. The data were evaluated in accordance with the stages of the content analysis method. As a result of the research, it was determined that 43 different theses about fluent reading have been prepared since 2009. It has been observed that a thesis about fluent reading was prepared most in 2019 and these theses were mostly carried out in Gazi University's postgraduate programs. In addition, it was determined that the topic of developing fluent reading skills was preferred in theses on fluent reading. It is determined that quantitative research patterns are applied in the theses on reading fluent reading. In addition, it was determined that tools using such as scale, test and inventory.
\end{abstract}

Keywords: Reading, fluent reading, thesis, tendency, descriptive analysis.

\section{Giriş}

Okuma, en temel bilgi edinme yollarındandır. Okuma, kâğıt ya da ekran üzerindeki sembolleri anlamlandırma, içeriği ya da şifreyi çözme işidir. "Okuma işi, fizyolojik olarak görme ve seslendirmeden, ruhsal olarak da kavrama eyleminden oluşan bir süreçtir" (Göğüş, 1978: 60). Bilgi, deneyim ve

\footnotetext{
* Dr. Öğr. Gör., Giresun Üniversitesi Türk Dili Bölümü, Güre Yerleşkesi, Giresun, asli.maden@giresun.edu.tr, ORCID: orcid.org/0000-0002-3336-0198
} 
yaşantılara dair kaynaklardan yararlanmanın anahtarı olarak okuma, insan yaşamı için vazgeçilmez bir dil becerisidir.

Okuma, okul çağında ilkokuma ve yazma sürecinde edinilmeye başlanan sonrasında alışkanlığa dönüştürülmesi hedeflenen bir beceridir. Illkokuma sürecinde yazılı veya basılı olan metinlerin uygun sürede ve hızda, noktalama işaretlerine ve yazım kurallarına göre seslendirilmesi ve anlamın tam olarak kavranabilmesi beklenir. Çünkü okuyucunun metni uygun hızda ve ritimde seslendirmesi, okunan metinle ilgili zihinsel işlemlerin de doğru ilerleyebilmesini dolayısıyla anlamayı etkilemektedir. Nitekim okuma sürecinin nihai hedefi anlamı elde etmektir ve bu da metnin akıcı biçimde okunmasına bağlıdır.

Akıcı okuma, uygun hız, ritim ve sesletimle metni konuşuyor gibi okumadır. Akıcı okuma kelimelerin otomatik biçimde tanınması buna bağlı olarak doğru ifade ve tonlama ile seslendirilmesine dayanır (Akyol, 2006; Akyol ve Kodan, 2016; Bashir \& Hook, 2009; Fuchs, Fuchs, Hosp \& Jenkins, 2001; Keskin ve Akyol, 2014; Klauda \& Guthrie, 2008; Nichols, Rupley \& Rasinski, 2009; Nunez, 2009; Rasinski, 2004; Wilger, 2008; Young \& Rasinski, 2009). Yapılan tanımlamalar akıcı okumanın dört temel unsura dayandığını göstermektedir (Aktaş ve Çankal, 2019): Doğru Okuma (Harfleri doğru seslendirme), Anlama (Okunulandan sonuç çıkarma), Prozodi (Ritim, vurgu ve tonlamalı söyleme), Hız (Otomatik kelime tanıma). Bu unsurlar aynı zamanda akıcı okumanın edinim aşamalarını ve işleyişini de içermektedir.

Okunan metne dair zihindeki anlama eylemi de okuma ritmine ve hızına göre şekillenmekte ve ilerlemektedir. Okuma sürecinde akıcılık bozulduğunda anlama sürecinin aksayacağı bilinmelidir. Nitekim araştırmalar okuyucunun metnin anlamına yoğunlaşmak ve bu işlemi istekle yapıp alışkanlığa dönüştürebilmek için yeterli hız ve ritimde okuma yapması gerektiğini göstermektedir (Foorman, Koon, Petscher, Mitchell \& Truekenmiller, 2015; Kaya ve Yıldırım, 2018; Morris \& Gaffney, 2011; Paige, Rasinski \& Magpuri-Lavell, 2012; Paige \& Magpuri-Lavell, 2014; Piper \& Zuilkowski, 2015). Uygun hızda ve ritimde okumayanların daha sonraki okuma yaşantılarında hem okuma hem de anlama konusunda güçlük yaşayabileceği bilinmektedir (Baştuğ ve Demirtaş 2016; Güneş, 2007; Ülper ve Yağmur, 2016). İyi bir okuma için ses farkındalığı, ses, kelime tanıma, akıcı okuma ve anlamanın gerçekleşmesi (Kaya ve Yıldırım, 2018) ve bu bileşenlere yönelik becerilere sahip olunması gerekmektedir. Sözü edilen bileşenlerin hepsi dinamik bir ilişki içindedir. Bu nedenle sürecin etkili bir parçası olarak akıcı okuma sadece hızlı okumayı ya da hoşa gider seslendirmeyi içermez. Okuma sürecindeki ritim ve uygun akış, kelimeleri tanıyarak zihindeki karşılıkları ile eşleştirmeyi sağlar. Böylece okuma sürecindeki ilerleyiş beynin çalışmasına koşut biçimde ilerleyerek anlamayı kolaylaştırır.

Akıcı okuma, telaffuzu ve anlama yeteneğini, okumaya yönelik ilgi ve güdülenmeyi olumlu etkileyerek okuma alışkanlığını desteklemektedir. Dolayısıyla okuma becerisinin kazandırımasında temel teşkil edecek bir konumdadır. Akıcı okuma eğitiminin önemli bir basamağını oluşturmaktadır. Bu nedenle Türkçe öğretim programlarında da amaç ve içerik olarak yer bulmaktadır. Türkçe Dersi Öğretim Programı (MEB, 2019) ilk okuma ve yazma sürecinin Bağımsız Okuma ve Yazma aşamasında akıcı okuma ile ilgili olarak sessiz ve sesli okuma, sesleri doğru çıkarma, vurgu tonlama, anlamlı okuma, koro hâlinde okuma, metin üzerinde konuşma gibi öğretim etkinliklerinin yapılmasını önermektedir. Ayrıca 1. sınıftan 8.sınıfa kadar Akıcı Okuma başlığı altında kazanımlara yer verilerek bu beceriye dair amaçlar sarmal biçimde sunulmaktadır. Programda belirlenmiş hedeflere ve öğrenme-öğretme süreci açıklamalarına bağı olarak akıcı okuma eğitiminin gerçekleştirilmesi okuma alışkanlığının kazandırılmasında önem taşımaktadır. Bu doğrultuda alanyazında akıcı okuma becerilerinin geliştirilmesinde etkili olabilecek tekrarlı okuma, okuyucu tiyatroları, eko okuma, eşli okuma, paylaşarak okuma, kelime tekrar tekniği gibi strateji ve tekniklerine, bu stratejileri konu alan çeşitli araştırmalara rastlanabilmektedir (Aktaş ve Çankal, 2019; Akyol ve Kodan, 2016; Ellis, 2009; Herberg, McLaughlin, Derby \& Weber, 2012; Lerner, 2000; Rasinski, 1990; Yılmaz, 2006). Bunların dışında akıcı okumaya dair alanyazından farklı araştırmalara da ulaşılabilmektedir: Örneğin akıcı okumanın anlama ile iliş̧isini ortaya koyan (Baştuğ ve Keskin, 2012; Kaya ve Yıldırım, 2016, 2018; Lepola etc., 2016; Pey, Min \& Woh, 2014; Schall etc., 2016; Ulu, 2016; Utchell etc., 2016), okuma güçlüğü ile ilgili olan (Ekiz, Erdoğan ve Uzuner, 2011; Yüksel, 2010 gibi) ve yaşanan sorunlarla ilgili olan (Uzunkol, 2013 gibi) çalışmalar öne çıkmaktadır. Karagöz ve Şeref'in (2019) konuyla ilgili araştırmasında fonolojik farkındalık kavramının ve okuduğunu anlama ile ilişkisinin okuma üzerine yapılan araştırmalarda sıkça incelendiği 
tespit edilmiştir. Yine Alderson'a (2005) ve Yamaç ve Çeliktürk Zengin'e (2019) göre de akıcı okuma son dönemlerde ilgi gören bir araştırma konusudur. Ancak ülkemizde akıcı okuma ile ilgili yapılan araştırmaların eğilimlerini ortaya koyan bir çalışmaya alanyazından ulaşılamamaktadır. Bu durum akıcı okumaya dair araştırmalarla ilgili eğilimlerin belirlenmesini gerekli ve değerli kılmaktadır.

Bu araştırmada akıcı okuma ile ilgili lisansüstü tezlerin tespit edilmesi ve çeşitli açılardan analiz edilerek eğilimlerinin ortaya konulması amaçlanmıştır. Bu amaç doğrultusunda akıcı okuma ile ilgili tezlerin yıllara, türe, konuya, üniversiteye, yöntem ve desenlerine, veri toplama araçlarına ve analiz yöntemlerine göre dağılımı belirlenmiş ve eğilimleri ortaya konulmuştur.

\section{Araştırmanın Modeli}

\section{Yöntem}

Araştırmada nitel araştırma desenlerinden betimsel içerik analizi kullanılmıştır. İçerik analizi, "belirli kurallara dayalı kodlamalarla bir metnin bazı sözcüklerinin daha küçük içerik kategorileri ile özetlendiği sistematik, yinelenebilir bir tekniktir" (Büyüköztürk ve diğerleri, 2013: 250). "içerik analizinde temelde yapılan işlem, birbirine benzeyen verileri belirli kavramlar ve temalar çerçevesinde bir araya getirmek ve bunları okuyucunun anlayabileceği bir biçimde düzenleyerek yorumlamaktır." (Yıldırım ve Şimşek, 2008: 227). Diğer bir deyişle içerik analizi, bir alanda yapılmış olan alan yazını / literatürü incelemeye ve değerlendirmeye yardımcı olur. Çalık ve Sözbilir (2014), içerik analizi araştırmalarını üçe ayırır: meta-analiz, meta sentez (tematik) ve betimsel içerik analizi. Bu araştırma akıcı okumaya yönelik tezlerin eğilimleri hakkında bilgi verdiği için betimsel içerik analizine uygun bir süreç içermektedir. "Betimsel içerik analizi; belirli bir konu üzerinde yapılan çalışmaların ele alınıp eğilimlerinin ve araştırma sonuçlarının tanımlayıcı bir boyutta değerlendirilmesini içeren sistematik çalışmalardır." (Çalık ve Sözbilir, 2014: 34).

\section{Veri Kaynağı}

Bu araştırmanın veri kaynağını, YÖK Ulusal Tez Merkezinde yer alan ve paylaşıma açık olan akıcı okuma üzerine, 2020 yılına kadar, hazırlanmış ve hazırlanmakta olan lisansüstü tezler oluşturmaktadır.

Veri kaynağını oluşturan tezler, YÖK Ulusal Tez Merkezi genel ağ sayfası üzerinden belirli anahtar kavramlara göre taramalar yapılarak tespit edilmiştir. Okuma eğitimi, okuma ve akıcı okuma yöntem ve teknikleri ve türleri konularında araştırmaları olan Türkçe eğitimi uzmanlarının görüşleri doğrultusunda; akıcı okuma, prozodik okuma ve sesbilgisel farkındalık anahtar kavramları ile arama yapılması kararlaştırıımıştır. 29.12.2019-29.02.2020 tarihleri arasında yapılan taramada okuma becerisi ile ilgili olmayan konuşmaya dönük tezler dikkate alınmamıştır. Bu şekilde YÖK Ulusal Tez Merkezinde hazırlanmış 42 ve hazırlanmakta olan 1 teze ulaşılmıştır. Hazırlanmış tezlerin elektronik dosyaları edinilmiş ancak kısıtlanmış ve hazırlanmakta olan tezler için Tez Merkezinde yer alan tanıtıcı bilgiler ve özetten yararlanılmıştır. Belirlenen ölçütlere göre yapılan tarama sonucunda ulaşılan 43 lisansüstü tez araştırmanın veri kaynağını oluşturmuştur.

\section{Veri Toplama Aracı}

Araştırmada, yayın sınıflama formu kullanılmıştır. Form alanyazındaki, makaleler için geliştirilmiş olan bir sınıflama formundan (Sözbilir ve Kutu, 2008) yararlanılarak hazırlanmıştır. Form çalışmanın amaç ve içeriğine uygun olarak düzenlenmiştir. Akıcı Okuma ile ilgili Tezleri Sınıflama Formunun geçerliliği için Türkçe eğitimi uzmanlarının $(n=3)$ görüşleri alınmıştır. Taslak formun tezleri sınıflandırmada yeterli olacağı görüşü hâkim olmuştur. Seçkisiz olarak seçilen 5 tez üzerinde taslak formun ön uygulaması yapılmıştır. Ön uygulama sonrası formun güvenilirliğini test etmek için değerlendirmeciler $(n=2)$ arasındaki tutarlılığa (görüş birliği + görüş ayrılı̆̆ı) bakılmıştır. Değerlendirmeciler arasındaki aykırılıkları belirlemek için değerlendirme formları karşılaştırılmıştır. Yapılan sınıflandırmalara ilişkin eksiklikler belirlenmiştir. Formun bölümleri ve verilerin sınıflandııılması ile ilgili ortaya çıkan sınıflama sorunları (veri analizi yöntemi gibi), uzmanların görüşü doğrultusunda düzeltilerek forma son biçimi verilmiştir. Tez sınıflama formu veri kaynağının hazırlandığı yılı ve 
üniversitesi, türü, konusu, yöntemi, örneklemi, veri toplama araçları ve veri analiz yöntemi olmak üzere yedi bölümden oluşmaktadır.

\section{Verilerin Analizi}

Veriler betimsel içerik analizi yönteminin aşamalarına uygun olarak değerlendirilmiş̧ir. İçerik analizi elde edilen verilerin kodlanması, sınıflanması ve tanımlanması aşamaları izlenerek gerçekleşir (Glesne, 2012). Betimsel içerik analizinde bu süreç izlenerek bir konuyla ilgili çalışmaların eğilimlerini tanımlayıcı biçimde ortaya koymak amaçlanmaktadır. Bu doğrultuda, analiz sürecinde her bir tez türüne, yılına, üniversitesine, konusuna, araştırma yöntemine, örneklemine, veri toplama araçlarına ve veri analiz yöntemlerine göre sınıflandırımıştır. Veriler SPSS 16.0 programı kullanılarak kodlanmıştır. illk aşamada veri kaynağının künyesine (adı, yazarı, yayımlandığı yıl, üniversite vb.) ilişkin veri girişi yapılmış daha sonra türü, konusu, yöntemi, örneklem, veri toplama araçları ve veri analiz yöntemleri tespit edilmiştir. Bu aşamalar izlenirken bazı tezlerde yöntem, veri toplama araçları ve analiz yöntemleri ile ilgili yeterli bilginin olmadığı görülmüştür. Bu konu hakkında alan uzmanlarının görüşüne başvurulmuş ve alınan görüşler doğrultusunda veriler kodlanmıştır. SPSS 16.0 programına kodlanan veriler betimsel analiz tekniklerinden frekans kullanılarak yorumlanmıştır. Ulaşılan bulgular tablolar hâlinde sunulmuştur.

\section{Bulgular}

Akıcı okuma ile ilgili 43 farklı tezin analizine dair sayısallaştırılmış sonuçlar 7 alt başlıkta incelenmiştir.

\section{Tezlerin Yıllarına İlişkin Bulgular}

Yayımlanan tezlerin yayımlanma yıllarına ilişkin dağııım Tablo 1'de görselleştirilmiştir: Tablo 1.

Akıcı okuma ile ilgili tezlerin yıllara göre dağılımı

\begin{tabular}{cc}
\hline YIl & $f$ \\
\hline 2009 & 2 \\
2011 & 1 \\
2012 & 3 \\
2013 & 1 \\
2014 & 2 \\
2015 & 2 \\
2016 & 2 \\
2017 & 7 \\
2018 & 6 \\
2019 & 17 \\
Toplam & 43 \\
\hline
\end{tabular}

Tablo 1'de akıcı okuma ile ilgili tezlerin yıllara dağılımı görülmektedir. Bulgulara göre ilk tezin 2009 yılına tarihlendiği belirlenmiştir. Yayım yıllarına göre en fazla tezin 2019 ( $f=17)$ yılında, bunu takiben 2017 ( $f=7)$ ve 2018 ( $f=6$ ) yıllarında hazırlandığı anlaşılmaktadır. Diğer yıllarda 1 ile 3 arasında tezin hazırlandığı tespit edilmiştir. Bunlarla birlikte, son yıllarda akıcı okuma ile ilgili tez çalışmalarındaki artışın dikkat çekici olduğu söylenebilir.

\section{Tezlerin Türlerine İlişkin Bulgular}

Yayımlanan tezlerin türlerine ilişkin dağıım Tablo 2'de görselleştirilmiştir:

Tablo 2.

Akıcı okuma ile ilgili tezlerin türe göre dağılımı

\begin{tabular}{cc}
\hline Tür & $f$ \\
\hline Yüksek Lisans & 28 \\
\hline
\end{tabular}




\begin{tabular}{ll}
\hline Doktora & 15 \\
Toplam & 43 \\
\hline
\end{tabular}

Tablo 2' de akıcı okuma ile ilgili tezlerin 28'inin yüksek lisans, $15^{\prime}$ inin doktora türünde olduğu görülmektedir. Bu bulguya göre, akıcı okuma ile ilgili tezlerin çoğunluğun yüksek lisans düzeyinde hazırlanmıştır.

Tezlerin Konu Alanlarına İlişkin Bulgular

Yayımlanan tezlerin konu alanlarına ilişkin dağııım Tablo 3'te görselleştirilmiştir:

Tablo 3.

Akıcı okuma ile ilgili tezlerin konularına göre dağılımı

\begin{tabular}{lc}
\hline Konu & $f$ \\
\hline Akıcı okuma düzeyinin tespiti & 7 \\
Akıcı okuma becerisini geliştirme & 11 \\
Akıcı okuma ve anlama arasındaki ilişki & 7 \\
Akıcı okuma anlama, motivasyon ve tutum ilişkisi & 4 \\
Akıcı okuma fonolojik farkındalık ilişkisi & 5 \\
Akıcı okuma ve okuma/öğrenme güçlüğü & 7 \\
Ölçek geliştirme & 1 \\
Akıcı okumaya yönelik görüş & 1 \\
\end{tabular}

Tablo 3'te akıcı okuma ile ilgili tezlerin konu alanlarına ilişkin dağıımı görülmektedir. Bulgulara göre, akıcı okuma üzerine hazırlanan tezlerin en fazla akıcı okuma becerisini geliştirme ( $\mathrm{f}=11)$, daha sonra akıcı okuma düzeyinin tespiti, akıcı okuma ve anlama arasındaki ilişki, akıcı okuma ve okuma/öğrenme güçlüğü $(\mathrm{f}=7)$ konu alanlarında yoğunlaştığı anlaşılmaktadır. Bunların dışında akıcı okuma anlama, motivasyon, tutum ilişkisi ve akıcı okuma fonolojik farkındalık ilişkisi önde gelen konular arasındadır. Ayrıca ölçek geliştirme ve akıcı okumaya yönelik görüşleri belirlemeyi konu alan birer tezin olduğu da tespit edilmiştir. Bu bulgu, lisansüstü tez araştırmalarında akıcı okuma becerisini geliştirmenin önemsendiğini ve bu amaçla ilgili durumu ortaya koymak için düzey / durum tespitinin yapıldığını yine anlama ilişkisinin de dikkate alındığını göstermektedir.

\section{Tezlerin Hazırlandığı Üniversitelere İlişkin Bulgular}

Yayımlanan tezlerin hazırlandığı üniversitelere ilişkin dağılım, alfabetik sırasıyla, Tablo 4'te görselleştirilmiştir:

Tablo 4.

Akıcı okuma ile ilgili tezlerin üniversitelere göre dağılımı

\begin{tabular}{lc}
\hline Üniversiteler & $f$ \\
\hline Anadolu Üniversitesi & 2 \\
Ankara Üniversitesi & 3 \\
Bayburt Üniversitesi & 1 \\
Boğaziçi Üniversitesi & 1 \\
Bolu Abant iB Üniversitesi & 2 \\
Erciyes Üniversitesi & 1 \\
Erzincan BY Üniversitesi & 1 \\
Eskişehir OG Üniversitesi & 2 \\
Gazi Üniversitesi & 11 \\
\hline
\end{tabular}




\begin{tabular}{lc}
\hline Hacettepe Üniversitesi & 2 \\
İstanbul Üniversitesi & 1 \\
İstanbul Aydın Üniversitesi & 1 \\
İstanbul Cerrahpaşa Üniversitesi & 1 \\
Kırıkale Üniversitesi & 1 \\
Kırşehir Ahi Evran Üniversitesi & 3 \\
Konya NE Üniversitesi & 2 \\
Niğde ÖHD Üniversitesi & 2 \\
Ondokuz Mayıs Üniversitesi & 1 \\
Ordu Üniversitesi & 1 \\
Pamukkale Üniversitesi & 1 \\
RTE Üniversitesi & 2 \\
Uşak Üniversitesi & 1 \\
Toplam & 43 \\
\hline
\end{tabular}

Tablo 4'te akıcı okuma ile ilgili tezlerine hazırlandığı üniversiteler görülmektedir. Bulgulara göre, akıcı okuma üzerine en fazla tezin Gazi Üniversitesi'nde hazırlandığı tespit edilmiştir. Gazi Üniversitesi'nden sonra Ankara ve Kırşehir Ahi Evran Üniversitelerinde de 3; Anadolu, Bolu Abant izzet Baysal, Eskişehir Osmangazi, Hacettepe, Konya Necmettin Erbakan, Niğde Ömer Halisdemir, Recep Tayyip Erdoğan Üniversitelerinde ise 2 adet tezin akıcı okuma ile ilgili olarak hazırlanmış olduğu da görülmektedir. Bunların dışında 12 farklı üniversitede ise akıcı okuma ile ilgili birer tezin hazırlandığı ulaşılan bulgular arasındadır. Bu bulgu, akıcı okumanın lisansüstü düzeyde daha çok Gazi Üniversitesi'nde araştırmalara konu edildiğini, ilgili üniversitesinin Sınıf Eğitimi, Türkçe Eğitimi Ana Bilim Dallarında konuyla ilgilenen ve öğrencilerinin de bu alanın ihtiyaçları doğrultusunda uzmanlaşmasını isteyen araştırmacıların olduğunu göstermektedir. Yine akıcı okuma ile ilgili lisansüstü tezlerin Ankara ve çevresindeki illerde yoğunlaşması da bahsedilen üniversiteler ile olan akademik bağ veya iş birliğine bağlanabilir.

\section{Tezlerin Araştırma Yöntemlerine iliş̧kin Bulgular}

Yayımlanan tezlerin araştırma yöntem ve desenlerine ilişkin dağılım Tablo 5 'te görselleştirilmiştir:

Tablo 5.

Akıcı okuma ile ilgili tezlerin araştırma yöntemlerine göre dağılımı

\begin{tabular}{|c|c|c|c|}
\hline Araştırma Yöntemi & & Desen & $f$ \\
\hline \multirow{6}{*}{ Nicel } & Deneysel & Yarı Deneysel & 13 \\
\hline & & Tarama & 16 \\
\hline & & Ölçek Geliştirme & 1 \\
\hline & $\begin{array}{l}\text { Deneysel } \\
\text { Olmayan }\end{array}$ & Nedensel Karşılaştırma & 1 \\
\hline & & Tek Denekli & 2 \\
\hline & & Ara Toplam & 33 \\
\hline \multirow{4}{*}{ Nitel } & & Fenomenoloji & 1 \\
\hline & & Durum & 1 \\
\hline & & Eylem Araştırması & 3 \\
\hline & & Ara Toplam & 5 \\
\hline
\end{tabular}




\begin{tabular}{lcc}
\hline Nicel + Nitel & Karma & 5 \\
\hline & Toplam & 43 \\
\hline
\end{tabular}

Tablo 5'te akıcı okuma ile ilgili tezlerin araştırma yöntem ve desenlerine ilişkin bulgular görülmektedir. Bulgulara göre, akıcı okuma ile ilgili tezlerin 33'ü nicel, $5^{\prime}$ i nitel ve $5^{\prime}$ i de karma yöntemle gerçekleştirilmiştir. Tabloya göre akıcı okumayla ilgili tezlerde nicel araştırma desenlerinden 13'ü deneysel, 16'sı tarama, $1^{\prime} i$ ölçek geliştirme, $1^{\prime}$ i nedensel karşılaştırma ve $1^{\prime} i$ ise tek denekli araştırma ile yürütülmüştür. Nitel araştırma desenlerinden ise en fazla eylem araştırması $(f=3)$ tercih edilmiş, bunun yanında 1 fenomenoloji, 1 de durum çalışması yapılmışır. 5 tezin ise karma yöntemle hem nitel hem nicel desenlerden yararlandığı belirlenmiştir. Bu bulgu, deneysel ve eylem araştırması desenindeki çalışmalarla konu dağılımındaki akıcı okuma becerisinin geliştirilmesini; tarama ve fenomenoloji, durum çalışmalarıyla ise akıcı okuma ile ilgili düzey tespitini açıklamaktadır. Yine akıcı okuma ile anlama ve okuma güçlüğü ilişkisinin de konu olarak fazla tercih edilmesi araştırma yöntemleri arasında taramanın daha çok yer almasını beraberinde getirmiştir.

Tezlerin Örneklem Özelliklerine ilişkin Bulgular

Yayımlanan tezlerin örneklem özelliklerine ilişkin dağıım Tablo 6' da görselleştirilmiştir:

Tablo 6.

Akıcı okuma ile ilgili tezlerin örneklem düzeyine göre dağılımı

\begin{tabular}{|c|c|c|c|c|c|c|c|c|c|c|c|c|c|}
\hline 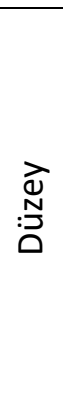 & 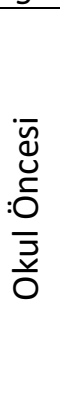 & $\begin{array}{l}\stackrel{4}{\leftrightarrows} \\
\bar{n} \\
-i\end{array}$ & $\begin{array}{l}\frac{4}{\Xi} \\
\bar{n} \\
\end{array}$ & $\begin{array}{l}\stackrel{4}{\bar{\Xi}} \\
\bar{n} \\
m\end{array}$ & $\begin{array}{l}\stackrel{4}{\Xi} \\
\bar{\Xi} \\
\dot{\sigma}\end{array}$ & 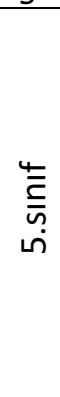 & 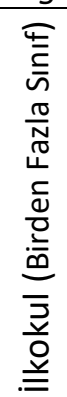 & $\begin{array}{l}\overline{\bar{z}} \\
\frac{\bar{v}}{0} \\
\mathbb{T} \\
\overline{0}\end{array}$ & 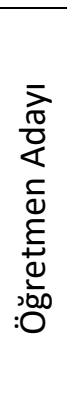 & 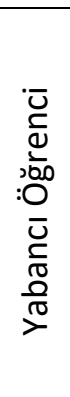 & 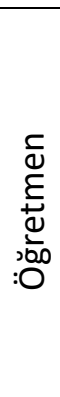 & 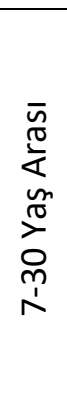 & $\begin{array}{l}\frac{\varepsilon}{0} \\
\frac{\pi}{0} \\
\circ\end{array}$ \\
\hline$f$ & 1 & 4 & 3 & 8 & 13 & 2 & 4 & 3 & 2 & 1 & 1 & 1 & 43 \\
\hline
\end{tabular}

Tablo 6'da akıcı okuma ile ilgili tezlerin örneklem özelliklerine ilişkin bulgular görülmektedir. Bulgulara göre, akıcı okuma ile ilgili tezlerin daha çok 4. sınıf öğrencilerini örneklem olarak seçtiği görülmektedir. Ayrıca 1, 2, 3, 5. sınıflarda ve ilkokul düzeyinde birden fazla sınıf öğrencisi üzerinde araştırma yapan tez sayısı da ( $f=21$ ) düşünüldüğünde, akıcı okuma ile ilgili daha çok ilkokul düzeyinde tez hazırlandığı söylenebilir. Bunların dışında okul öncesi, ortaokul, öğretmen adayı, öğretmen, yabancı öğrenci ve yetişkinleri örneklem olarak belirlemiş akıcı okuma tezlerinin yapıldığı da ulaşılan bulgular arasındadır. Bu bulgu, akıcı okuma eğitiminin ilkokul 1. sınıfta başlamasına ve devamında geliştirilmesi ile ilgili uygulamalara uygundur. Zira akıcı okuma ilkokuma döneminde kazandırılması hedeflenen bir okuma becerisidir.

\section{Tezlerin Veri Toplama Araçlarına ilişskin Bulgular}

Akıcı okuma ile ilgili tezlerin önemli bir kısmında birden fazla ölçme aracının kullanıldığı tespit edilmiştir. Bu nedenle veri analizinde ölçme araçlarının frekans değerleri belirlenerek çözümleme yapılmıştır. Yayımlanan tezlerin veri toplama araçlarına ilişkin dağılım Tablo 7'de görselleştirilmiştir:

Tablo 7.

Akıcı okuma ile ilgili tezlerin veri toplama araçlarının göre dağılımı

\begin{tabular}{|c|c|c|c|c|c|c|}
\hline $\begin{array}{c}\text { Veri Toplama } \\
\text { Araçları }\end{array}$ & $\begin{array}{l}\text { Başarı } \\
\text { Test }\end{array}$ & Ölçek & $\begin{array}{c}\text { Hata } \\
\text { Envanteri }\end{array}$ & $\begin{array}{l}\text { Görüşme } \\
\text { Formu }\end{array}$ & $\begin{array}{l}\text { Açık Uçlu } \\
\text { Soru }\end{array}$ & $\begin{array}{c}\text { Diğer } \\
\text { (Kontrol Listesi, Rubrik, } \\
\text { Gözlem Formu) }\end{array}$ \\
\hline
\end{tabular}




\begin{tabular}{lllllll}
\hline $\mathrm{f}$ & 16 & 22 & 10 & 9 & 9 & 8 \\
\hline
\end{tabular}

Tablo 7'de akıcı okuma ile ilgili tezlerin veri toplama araçlarına ilişkin bulgular yer almaktadır. Bulgulara göre, akıcı okuma ile ilgili tezlerde veri toplamak için en fazla ölçek ( $f=22$ ) tipi araçlara başvurulmuştur. Daha sonra başarı testi $(f=16)$, hata envanteri $(f=10)$, görüşsme formu ve açık uçlu soru $(f=9)$ ve kontrol listesi, rubrik ve gözlem formu $(f=8)$ gibi diğer araçlar gelmektedir. Bu bulgu, akıcı okuma ile ilgili tezlerin konu alanları arasında yer alan beceri geliştirme, düzeyi tespiti, akıcı okuma ve anlama arasındaki ilişki, okuma/öğrenme güçlüğü, anlama, motivasyon, tutum ve fonolojik farkındalık ilişkiye dair çalışmaları açıklamaktadır.

\section{Tezlerin Veri Analiz Yöntemlerine iliş̧in Bulgular}

Akıcı okuma ile ilgili tezlerin önemli bir kısmında birden fazla veri analiz yönteminin kullanıldığı tespit edilmiştir. Bu nedenle veri analiz yöntemlerinin frekans değerleri belirlenerek çözümleme yapılmıştır. Yayımlanan tezlerin veri analiz yöntemlerine ilişkin dağıım Tablo 8'de görselleştirilmiştir:

Tablo 8.

Akıcı okuma ile ilgili tezlerin veri analiz yöntemlerine göre dağıımı

\begin{tabular}{|c|c|c|c|}
\hline \multicolumn{3}{|c|}{ Veri Analiz Yöntemleri } & $f$ \\
\hline \multirow{8}{*}{ Nicel } & \multirow{2}{*}{ Betimsel } & Frekans / yüzde & 4 \\
\hline & & Ortalama / Standart Sapma & 17 \\
\hline & \multirow{6}{*}{ Kestirimsel } & Non-parametrik testler & 19 \\
\hline & & Faktör Analizi & 1 \\
\hline & & t test & 13 \\
\hline & & Ki-kare & 1 \\
\hline & & Anova, Ancova & 10 \\
\hline & & Korelasyon, Regresyon & 15 \\
\hline \multirow{2}{*}{ Nitel } & \multirow{2}{*}{ Nitel } & İçerik Analizi & 10 \\
\hline & & Betimsel Analiz & 5 \\
\hline
\end{tabular}

Tablo 8'de akıcı okuma ile ilgili tezlerin veri analiz yöntemlerine ilişkin bulgular görülmektedir. Bulgulara göre, akıcı okuma ile ilgili tezlerde kestirimsel istatistik tekniklerden en fazla non-parametrik testler $(f=19)$, betimsel tekniklerden ise ortalama-standart sapma $(f=17)$ kullanılmıştır. Bunların yanında kestirimsel tekniklerden korelasyon analizi, Anova ve $t$ test de daha çok tercih edilmiştir. Nitel istatistik tekniklerden ise en fazla içerik analizine $(f=10)$ sıklıkla başvurulmuştur. Bu bulgu akıcı okuma ile ilgili tezlerde nicel analiz tekniklerinin kullanımına dair bir eğilim olduğunu göstermektedir. Ulaşılan bulgu akıcı okuma becerisinin geliştirilmesi, ölçümü ve etkili değişkenlerin tespitine dair yapılacak çalışmaların nicel tekniklere ihtiyaç duyması ile açıklanabilir.

Tartışma ve Sonuç

Akıcı okuma ile ilgili lisansüstü tezleri belirlemeyi ve çeşitli özelliklerini analiz ederek eğilimlerini ortaya koymayı amaçlayan bu araştırmada şu sonuçlara ulaşılmışır:

Akıcı okuma ile ilgili bugüne kadar 28'si yüksek lisans, 15'i doktora türünde olmak üzere 43 farklı lisansüstü tezin hazırlandığı tespit edilmiştir. Ayrıca akıcı okuma ile ilgili ilk lisansüstü çalışmanın ise 2009 yııında, en fazla tez çalışmasının ise 2019 yılında gerçekleştirildiği görülmüştür. 2018 ve 2017 yıllarında da geçmiş yıllara göre daha fazla tezin üretilmiş olması, sonrasında ise 2019 yılında 17 tezin üretilmesi dikkat çeken sonuçlardandır. Bu sonuç, akıcı okuma ile ilgili lisansüstü çalışmalarının sınırlı olduğunu ve son yıllarda bir artış eğilimin sergilendiğini göstermektedir. Ceran ve diğerlerinin (2018) okuma eğitimi ile ilgili lisansüstü tezlere dair içerik analizine dayalı araştırmasında, ilk tez çalışmasının 2016 yııında, en fazla tez çalışmasının ise 2013 yılında yapıldığının tespit edilmesi akıcı okuma ile okuma eğitimi araştırmalarının eğilimlerinin farklılaştığına işaret etmektedir. Ancak aynı araştırmada yüksek lisans tezlerinin daha yapıldığının belirlenmesi ulaşılan sonuçları desteklemektedir. 
Akıcı okuma ile ilgili tezlerde akıcı okuma becerisini geliştirme konusunun daha fazla tercih edildiği tespit edilmiştir. Bunun dışında ise akıcı okuma ile ilgili düzey tespiti yapmaya; anlama, okuma güçlüğü, motivasyon, tutum ve fonolojik farkındalık arasındaki ilişkiyi ortaya koymaya dair bir eğilimin tezlerde hâkim olduğu görülmüştür. Ceran ve diğerlerinin (2018) araştırmasında okuma yöntem ve teknikleri konusunun ilk sırada yer alması, Akaydın ve Çeçen'in (2015) araştırmasında ise, okuma beceri düzeyi ve okuma güçlüğü konularının makalelerde tercih edilmesi araştırmanın konu alanlarını destekler niteliktedir. Varışoğlu ve diğerlerinin (2013) Türkçe eğitimi araştırmalarının eğilimlerine yönelik araştırmasında, bu alanda yapılan çalışmalarda konu olarak en fazla okuma eğitiminin tercih edildiğinin belirlenmesi hem araştırma amacını hem de konu alanlarına dair sonuçlarını temellendirmektedir. Alanyazındaki konuyla ilgili araştırmalarda da akıcı okuma becerisinin geliştirilmesine önem verilmesi, ilke ve yöntemlerinin açıklanması da konuya dair eğilimi açıklamaktadır (Hubhard, 2009; Rasinski etc., 2005; Rasinski, 2006; Reutzel \& Cooter, 1996; Samuel, 2006; Samuel \& Farstrup, 2006; Rasinski, T., Samuels, Hiebert, Petscher \& Feller, 2011; Therrien, 2004).

Araştırma kapsamında ulaşılan akıcı okuma ile ilgili çalışmaların 22 farklı üniversitenin lisansüstü programlarında hazırlandığı belirlenmiştir. Akıcı okuma üzerine en çok tez çalışmasının Gazi Üniversitesi'nde yapıldığı görülmüştür. Ancak akıcı okumaya yönelik ilk tezler Hacettepe Üniversitesi'nde hazırlanmıştır. Gazi Üniversitesi'ni Ankara ve Kırşehir Ahi Evran Üniversiteleri takip etmektedir. Bunların yanında Anadolu, Bolu Abant İzzet Baysal, Eskişehir Osmangazi, Hacettepe, Niğde Ömer Halisdemir, Recep Tayyip Erdoğan Üniversitelerinde de birden fazla sayıda akıcı okuma konulu tez hazırlandığı ulaşılan sonuçlar arasında yer almaktadır. Gazi Üniversitesi'nde okuma eğitimi ile ilgili diğer üniversitelerden daha fazla tez üretildiğini Ceran ve diğerlerinin (2018), daha fazla makale üretildiğini ise Akaydın ve Çeçen'in (2015) tespitleri ortaya koymaktadır. Dolayısıyla akıcı okumayla beraber okuma eğitimi ile ilgili tez ve makaleler konusunda da Gazi Üniversitesi'nin başı çektiği söylenebilir. Bu sonuç, Türkçe Eğitimi ile ilgili lisansüstü programların ilk kez 1989 yılında Gazi Üniversitesi'nde açılması (Güzel, 2003: 15) ve Türkçe eğitimi alanında lisansüstü öğrenci yetiştirmeye başlanması ile açıklanabilir. Yine Güzel'in (2003) ifadesiyle, bahsedilen program 1995-1996 yılından itibaren "Türkçe'nin Eğitimi-Öğretimi" alanında bir merkez konumuna gelmiştir.

Akıcı okumaya yönelik tez çalışmalarının çoğunluğunun nicel araştırma desenlerinde gerçekleştirildiği tespit edilmiştir. Bu araştırmalar içinde ise, deneysel ve tarama yöntemlerine göre yürütülenler başta gelmektedir. Nitel araştırma yöntemi ile gerçekleştirilen tezlerde daha çok eylem araştırmasının kullanılması ise dikkat çeken sonuçlardandır. Ceran ve diğerlerinin (2018) araştırmalarında, nicel araştırma desenlerinin daha çok tercih edilmesi araştırmayla örtüşmektedir. Akaydın ve Çeçen'in (2015) okuma becerisiyle ilgili makaleler üzerine yaptığı içerik analizi çalışmasında da incelenen makalelerinin çoğunda nicel yöntemlerden taramanın tercih edilmesi araştırmayı desteklemektedir. Göktaş ve diğerlerinin (2012) eğitim bilimlerine dair araştırmalarının eğilimlerini analiz ettiği araştırmasında, Türkiye'deki eğitim araştırmalarında da daha çok nicel yöntemin tercih edilmesi ulaşılan sonuçları açıklamaktadır.

Araştırma kapsamında analize tabi tutulan tezlerin yarısından fazlasının ilkokul düzeyinde gerçekleştirildiği belirlenmiştir. Ayrıca tezlerin önemli bir kısmında 4. sınıf öğrencileri örneklem olarak seçilmiştir. Ceran ve diğerlerinin (2018) araştırmasında ise, okuma eğitimi ile ilgili tezlerde ilk olarak ortaokul düzeyinin örnekleme alındığı daha sonra ilkokul öğrencilerinin geldiğinin belirlenmesi, Akaydın ve Çeçen'in (2015) çalışmasında da ortaokulların örneklem olarak daha fazla tercih edilmesi bu araştırmanın bulguları ile örtüşmemektedir. Ancak okuma eğitimi ile ilgili eğitim süreci düşünüldüğünde, 5. sınıftan itibaren ortaokul kademesinde, akıcı okumanın dışında okuduğunu anlama, değerlendirme ve alışanlık boyutuyla, daha sistemli bir okuma eğitiminin gerçekleştiği görülecektir. Bu durum ilgili araştırmada örnek olarak öncelikle ortaokul öğrencilerine yönelik bir eğilimin varlığını açıklamaktadır. Varışoğlu ve diğerlerinin (2013) araştırmasında, analize tabi tutulan çalışmaların daha çok ilköğretim düzeyini örnekleme alması da araştırmayı desteklemektedir.

Akıcı okuma ile ilgili tezlerde veri toplama sürecinde daha çok ölçek tipi araçların kullanıldığı görülmüştür. Ölçek tipi araçlarının dışında tezlerde başarı testi, hata envanteri, görüşme formu, kontrol listesi, rubrik, gözlem formlarına veri toplamak için başvurulduğu gözlenmiştir. Bahsedilen ölçme araçları ile elde edilen verilerin analizinde ise, non-parametrik istatistik analiz tekniklerine daha çok 
başvurulmuştur. Ayrıca ortalama ve standart sapma, korelasyon, Anova ve $t$ testi gibi nicel teknikler, nitel analiz tekniklerinden ise içerik analizini kullanan tezler çoğunluktadır. Akaydın ve Çeçen'in (2015) araştırmasında en fazla tutum, algı ölçeklerinin ve testlerin ayrıca ortalama, $t$ test ve Anova istatistik tekniklerinin de kullanıldığının belirlenmesi araştırmayla aynı doğrultudadır. Varışoğlu ve diğerlerinin (2013) araştırmasında, nicel yöntemlerden taramanın kullanıldığını tespit etmesi de bu sonuçları desteklemektedir. Göktaş ve diğerlerinin (2012) veri toplama araçlarına dair ulaştığı sonuçlar da araştırmayla örtüşmektedir.

Araştırma sonucunda, akıcı okuma ile ilgili 2009 yılından bu yana 43 farklı tezin hazırlandığı tespit edilmiştir. Akıcı okumayla ilgili en fazla 2019 yılında tez hazırlandığı, bu tezlerin daha çok Gazi Üniversitesi'nin lisansüstü programlarında gerçekleştirildiği görülmüştür. Bununla birlikte akıcı okumaya dair tezlerde daha çok akıcı okuma becerisini geliştirme, akıcı okuma düzeyi; akıcı okumanın anlama, okuma güçlüğü, motivasyon, tutum ve fonolojik farkındalıkla ilişkisi konularının işlendiği ortaya konmuştur. Ulaşılan sonuçlar akıcı okumaya yönelik 2009-2019 yılları arasında hazırlanan tezlerde nicel araştırma desenlerine, bu desenlere bağlı olarak ise ölçek, test, envanter gibi araçların kullanılmasına ve kestirimsel istatistiklere başvurulmasına dair bir eğilimin olduğunu göstermektedir.

\section{Öneriler}

Araştırma sonuçlarından hareketle; akıcı okuma ile ilgili ilkokuldan ortaöğretime kadar farkı amaç ve örneklem özelliklerine yönelik çalışmaların yapılması, akıcı okuma ile ilgili yaşanan sorunlar ve sebep olan etkenlerin belirlenmesi, sınıf ve Türkçe öğretmeni adaylarının ve görev yapmakta olan öğretmenlerin akıcı okuma öğretimine yönelik yeterliliklerinin tespit edilmesi ve yapılan tespitler doğrultusunda hizmet öncesinde ders içeriği hazırlanması, hizmet içinde ise kurs verilmesi gibi önerilerde bulunulabilir.

\section{Kaynaklar}

Akaydın, Ş. ve Çeçen, M.A. (2015). Okuma becerisiyle ilgili makaleler üzerine bir içerik analizi. Eğitim ve Bilim, 40(178), 183-198.

Aktas, E. ve Çankal, A. O. (2019). Akıcı Okuma stratejilerinin 4.sınıf Türkçe derslerinde okuduğunu anlama becerisine ve okuma motivasyonuna etkisi. Zeitschrift Für Die Welt Der Türken / Journal of World of Turks 11(1), 85-114.

Akyol, H. (2006). Türkçe ilk okuma yazma öğretimi. Ankara: PegemA Yayıncılık.

Akyol, H. ve Kodan, H. (2016). Okuma güçlüğünün giderilmesine yönelik bir uygulama: Akıcı okuma stratejilerinin kullanımı. Ondokuz Mayıs Üniversitesi Eğitim Fakültesi Dergisi, 35(2), 7- 21.

Alderson, J. C. (2005). Assessing reading. Cambridge: Cambridge Universty Press.

Bashir, A. S. ve Hook, P. E. (2009). Fluency: A key link between word identification and comprehension. Language, Speech, and Hearing Services In Schools, 40, 196-200.

Baştuğ, M. ve Demirtaş, G. (2016). Child-centered reading intervention: See, talk, dictate, read, write!, International Electronic Journalof Elementary Education, 8(4), 601-616.

Baştuğ, M. ve Keskin, H.K. (2012). Akıcı okuma becerileri ile anlama düzeyleri (basit ve çıkarımsal) arasındaki ilişki. Ahi Evran Üniversitesi Kırşehir Eğitim Fakültesi Dergisi, 13(3), 227-244.

Büyüköztürk, Ş., Kılıç Çakmak, E., Akgün, Ö. A., Karadeniz, Ş. ve Demirel, F. (2013). Bilimsel araştırma yöntemleri. Ankara: Pegem Akademi Yayıncılık.

Ceran, D., Aydın, M. ve Onarıcıoğlu, A. S. (2018). Okuma eğitimi üzerine yapılan tezlerde eğilimler: bir içerik analizi çalışması Kırşehir Eğitim Fakültesi Dergisi, 19(3),2377-2392.

Çalık, M. ve Sözbilir, M. (2014). İçerik analizinin parametreleri. Eğitim ve Bilim, 39(174), 33-38.

Ekiz, D. (2009). Bilimsel araştırma yöntemleri. Ankara: Anı Yayıncılık.

Ekiz, D., Erdoğan, T. ve Uzuner, F. G. (2011). Okuma güçlüğü olan bir öğrencinin okuma becerisinin geliştirilmesine yönelik bir aksiyon araştırması. Abant İzzet Baysal Üniversitesi Eğitim Fakültesi Dergisi, 11(2), 111-131.

Ellis, W. A. (2009). The Impact of C-PEC (choral reading, partner reading, echo reading and performance of text) on third grade fluency and comprehension development. Doctoral dissertation. USA: University of Memphis. 
Foorman, B. R., Koon,S. K.,Petscher, Y., Mitchell, A. ve Truekenmiller, A. (2015).Examining general and specific factors in the dimensionalityof oral language and reading in $4^{\text {th }}-10^{\text {th }}$ grades, Journal of Educational Psychology, 107(3), 884-899.

Fuchs, L. S., Fuchs, D., Hosp, M. K., \& Jenkins, J. R. (2001). Oral reading fluency as an indicator of reading competence: A theoretical, empirical, and historical analysis. Scientific Studies of Reading, 5(3), 239-256.

Glesne, C. (2012). Nitel araştırmaya giriş. (Çev. Ed: A. Ersoy ve P. Yalçınoğlu), Ankara: Anı Yayıncılık.

Göğüş, B. (1978). Türkçe ve yazın eğitimi. Ankara: Gül Yayınevi.

Göktaş, Y., Hasançebi, F., Varışoğlu, B., Akçay, A., Bayrak, N., Baran, M. ve Sözbilir, M. (2012). Türkiye'deki eğitim araştırmalarında eğilimler: Bir içerik analizi. Kuram ve Uygulamada Eğitim Bilimleri Dergisi, 12(1), 177- 199.

Güneş, F. (2007). Ses temelli cümle yöntemi ve zihinsel yapılandırma. Ankara: Nobel Yayınları.

Güzel, A. (2003). Eğitim fakültelerinde Türkçe öğretmenliği bölümünün kuruluşu ve hedefleri -I-. Türklük Bilimi Araştırmaları (TÜBAR), XIII, 7-17.

Herberg, J., McLoughlin, T. F., Derby, K. M. \& Weber, K. P. (2012). The effects of repeated readings and flashcard error drill the reading accuracy and fluency with rural middle school student with learning disabilities. Academic Research International, 2(3), 388-393.

Hubhard, H. (2009). Readers theater: A means to improving the reading fluency rates of second and third grade students with learning disabilities. Master thesis. The California State University.

Kaptan, S. (1973). Bilimsel araştırma ve istatistik teknikleri. Ankara: Tekışık Yay.

Karagöz, B. ve Şeref, i. (2019). Okuma alanındaki araştırmaların bibliyometrik özellikler açısından incelenmesi. Ana Dili Eğitimi Dergisi, 7(3), 781-799.

Kaya, D. ve Yıldırım, K. (2016) Dördüncü sınıf öğrencilerin akıcı okumalarının basit ve çıkarımsal anlama düzeylerine göre değerlendirilmesi. Ana Dili Eğitimi Dergisi, 4(3), 416-430.

Kaya, D., ve Yıldırım, K. (2018). Akıcı okuma ve okuduğunu anlama arasındaki ilişkilerde cinsiyet nasıl bir rol oynamaktadır?. Journal of Human Sciences, 15(2), 931-942.

Keskin, H.K. ve Akyol, H. (2014). Yapılandırılmış okuma yönteminin okuma hızı, doğru okuma ve sesli okuma prozodisi üzerindeki etkisi. Ana Dili Eğitimi Dergisi, 2(4), 107-119.

Klauda, S. L., and Guthrie, J., T. (2008). Relationships of three components of reading fluency to reading comprehension. Journal of Educational Psychology, 100, 310-321. doi: 10.1037/00220663.100.2.310

Lepola, J., Lynch, J., Kiuru, N., Laakkonen, E. ve Nurmi, P. (2016). Early oral language comprehension, task orientation, and foundational reading skills as predictors of grade 3 reading comprehension. Reading Research Quarterly, 51(4), 373-390.

Lerner, J. (2000). Learning disabilities: Theories, diagnosis, and teaching strategies (8th ed.). Boston:Houghton Mifflin.

Millî Eğitim Bakanlığı [MEB] (2019). Türkçe dersi öğretim programı (ilkokul ve ortaokul 1, 2, 3, 4, 5, 6, 7 ve 8. siniflar). Ankara.

Morris, D. \& Gaffney, M. (2011). Building reading fluency in a learning-disabled middle school reader. Journal of Adolescent \& Adult Literacy, 54(5), 331-341.

Nichols, W. D., Rupley, W. H., \& Rasinski, T. (2009). Fluency in learning to read for meaning: Going beyond repeated readings. Literacy Research and Instruction, 48(1), 1-13.

Nunez, L. D. (2009). An analysis of the relationship of reading fluency, comprehension, and Word recognition to student achievement. Doctoral Dissertation, Tarleton State University.

Paige, D. D. \& Magpuri-Lavell, T. (2014). Reading Fluency in the middle and secondary grades. International Electronic Journal of Elementary Education, 7(1), 83-96.

Paige, D. D., Rasinski, T. V. \& Magpuri-Lavell, T. (2012). If fluent expressive reading important for high school readers? Journal of Adolescent \& Adult Literacy, 56, 67-76.

Pey. K.C., Min, L.H. \&Wah, L.L. (2014). Relationship between oral reading fluency and reading comprehension among ESL students. GEMA Online Journal of Language Studies, 14(3), 19-32. http://dx.doi.org/10.17576/GEMA-2014-1403-02. 
Piper, B. \& Zuilkowski, S.S. (2015). Assessing reading fluency in Kenya: Oral or silent assessment?. International Review of Education, 61(2), 153-171

Rasinski, T. (2006). Reading fluency instruction: Moving beyond accuracy, automaticity, and prosody. The Reading Teacher, 59(7), 704-706.

Rasinski, T. V. (1990). Effects of repeated reading and listening while reading on reading fluency. The Journal of Educational Research, 83 (3), 147-150.

Rasinski, T., Padak, N. D., McKeon, C. A., Wilfong, J. A., Friedauer, J.A. \& Heim, P. (2005). Is reading fluency a key for successful high school reading? Journal of Adolescent and Adult Literacy, 49(1), 22-27.

Rasinski, T., Samuels, S. J., Hiebert, E., Petscher, Y., \& Feller, K. (2011). The relationship between a silent reading fluency instructional protocol on students' reading comprehension and achievement in an urban school setting. Reading Psychology, 32, 75-97.

Rasinski, T.V. (2004). Creating fluent readers. Educational Leadership, 61, 46-51.

Reutzel, D. R. \& Cooter, R. B. (1996). Teaching children to read: From basals to books. Colombus: Merrill-Prentice Hall Publishing Company.

Samuel, S.J. (2006). Reading fluency. Rasinski,T., Blachowicz, C., \& Lems, K.(Ed.), Fluency instruction. The Gulford Press, London.

Schall, M., Skinner, J. H., Cazzell, S., Ciancio, D., Ruddy, J. \& Thompson, K. (2016). Extending Research on Oral Reading Fluency Measures, Reading Speed and Comprehension. Contemporary School Psychology, 20(3), 262-269.

Sözbilir, M. ve Kutu, H. (2008). Development and current status of science education research in Turkey. Essays in Education, [Special Edition], 1-22.

Therrien, W. J. (2004). Fluency and comprehension gains as a result of repeated reading: A Metaanalysis. Remedial and Special Education, 25(4), 252-261.

Ulu, M. (2016). İlkokul 4. sınıf öğrencilerinin akıcı okuma, basit anlama ve çıkarımsal anlama düzeylerinin problem çözme başarısına etkilerini açıklayan bir yapısal eşitlik modeli. Eğitim ve Bilim, 41(186), 93-117.

Utchell, L., A., Schmitt, A., J., McCallum, E., McGoey, K. E. \& Piselli, K. (2016). Ability of early literacy measures to predict future state assessment performance. Journal of Psychoeducational Assessment, 34(6), 511-523.

Uzunkol, E. (2013). Akıcı okuma sürecinde karşılaşılan sorunların tespiti ve giderilmesine yönelik bir durum çalışması. Mersin Üniversitesi Eğitim Fakültesi Dergisi, 9, 70-83.

Ülper, H. ve Yağmur, K. (2016). Akıcı sessiz sözcük okuma testinin geliştirilmesi. İlköğretim Online, 15(2), 581-593.

Varışoğlu, B., Şahin, A. ve Göktaş, Y. (2013). Türkçe eğitimi araştırmalarında eğilimler. Kuram ve Uygulamada Eğitim Bilimleri Dergisi, 13(3), 1767-1781.

Wilger, M. P. (2008). Reading fluency: A bridge from decoding to comprehension research brief. Ottawa: Outoskills.

Yamaç, A. ve Çeliktürk Sezgin, Z. (2018). İlkokul dördüncü sınıf öğrencilerinin okuma kaygıları, akıcılıkları, motivasyonları ve okuduğunu anlamaları arasındaki ilişkiler. Eğitim ve Bilim, 43(194), 225-243.

Yıldııım, A. ve Şimşek, H. (2011). Sosyal bilimlerde nitel araştırma yöntemleri. Ankara: Seçkin Yayıncılık.

Yılmaz, M. (2006). ilköğretim 3. Sınıf öğrencilerinin sesli okuma hatalarını düzeltmede ve okuduğunu anlama becerilerini geliştirmede tekrarlı okuma yönteminin etkisi. Yayınlanmamış doktora tezi. Gazi Üniversitesi, Ankara.

Young, C., \& Rasinski, T. (2009). Implementing readers theatreas an approach to classroom fluency Instruction. The Reading Teacher, 63(1), 4-13.

Yüksel, A. (2010). Okuma güçlüğü çeken bir öğrencinin okuma becerisinin geliştirilmesine yönelik bir çalışma. Kuramsal Eğitimbilim, 3(1), 124-134. 


\section{Incelenen Tezler}

1. Akyol, M. (2014). Yapılandırılmış akıcı okuma yönteminin üçüncü sını öğrencilerinin akıcı okuma ile okuduğunu anlama becerilerine etkisi. Yayımlanmamış yüksek lisans tezi. Niğde: Niğde Üniversitesi.

2. Özata, H. (2018). Reading fluency and comprehension in a transparent orthography: evidence from Turkish children. Yayımlanmamış doktora tezi. İstanbul: Boğaziçi Üniversitesi.

3. Esmer, B. (2019). Okuduğunu anlama ile akıcı okuma, okur benlik algısı, okumaya adanmışlık ve okuyucu tepkisi ilişkileri. Yayımlanmamış doktora tezi. Ankara: Gazi Üniversitesi.

4. Özhan, T. (2018). Illkokul 3. sınıf öğrencilerinin akıcı okuma becerilerinin ve anlama düzeylerinin incelenmesi. Yayımlanmamış yüksek lisans tezi. Samsun: Ondokuz Mayıs Üniversitesi.

5. Öztürk, M. (2019). Kelime duvarı yönteminin ilkokul 4. sınıf öğrencilerinin akıcı okuma ve okuduğunu anlama becerilerine etkisi. Yayımlanmamış yüksek lisans tezi. Bolu: Bolu Abant i̇zzet Baysal Üniversitesi.

6. Ege, B. (2019). Okuma güçlügünün giderilmesinde akıcı okuma stratejilerinin etkisi. Yayımlanmamış yüksek lisans tezi. Bayburt: Bayburt Üniversitesi.

7. Soydaş, B. (2019). Dijital metinleri tekrarlı okumanın ilkokul 4. sınıf öğrencilerinin akıcı okuma ve anlama becerileri üzerine etkisi. Yayımlanmamış yüksek lisans tezi. Ankara: Gazi Üniversitesi.

8. Kızıltaş, Y. (2019). Ana dili farklı ilkokul öğrencilerinin akıcı okuma ve okuduğunu anlama becerilerinin incelenmesi. Yayımlanmamış doktora tezi. Ankara: Gazi Üniversitesi.

9. Aşıkcan, M. (2019). Üçüncü sını öğrencilerinin akıcı okuma becerilerinin geliştirilmesine yönelik bir eylem araştırması. Yayımlanmamış doktora tezi. Konya: Necmettin Erbakan Üniversitesi.

10. Yılmaz Alkan, Z. (2019). ilkokul dördüncü sınıf öğrencilerinin akıcı okuma becerilerini geliştirmede tekerlemelerin etkisi. Yayımlanmamış yüksek lisans tezi. Ordu: Ordu Üniversitesi.

11. Saat, F. (2019). ilkokulda öz değerlendirmeye dayalı sesli okuma yönteminin akıcı okuma ve okuduğunu anlamaya etkisi. Yayımlanmamış yüksek lisans tezi. Niğde: Niğde Ömer Halis Demir Üniversitesi.

12. Çankal, A.O. (2018). Akıcı okuma stratejilerinin 4.sınıf Türkçe derslerinde okuduğunu anlama becerisine ve okuma motivasyonuna etkisi. Yayımlanmamış yüksek lisans tezi. Rize: Recep Tayyip Erdoğan Üniversitesi.

13. Görgün, B. (2018). Akıcı okuma ve okuduğunu anlama destek eğitim programının (oka dep) özel ögrenme güçlügü olan öğrencilerin okuma becerilerine etkisi. Yayımlanmamış doktora tezi. Eskişehir: Eskişehir Osmangazi Üniversitesi.

14. Kaya Tosun, D. (2018). Okuma Çemberlerinin Okuduğunu Anlama, Akıcı Okuma, Okuma Motivasyonu ve Sosyal Beceriler Üzerindeki Etkisi ve Okur Tepkilerinin Belirlenmesi. Yayımlanmamış doktora Tezi. Denizli: Pamukkale Üniversitesi.

15. Kanık Uysal, P. (2018). Akıcı okuma odaklı okuma öğretiminin beşinci sınıf öğrencilerinin okuma ve okuduğunu anlama becerileri üzerindeki etkisi. Yayımlanmamış doktora Tezi. Ankara: Gazi Üniversitesi.

16. Armut, M. (2017). Ortaokul öğrencilerinin akıcı okuma becerilerinin çeşitli değişkenler açısından incelenmesi (Yozgat ili örneği). Yayımlanmamış yüksek lisans tezi. Kırşehir: Ahi Evran Üniversitesi.

17. Arabacı, G. (2017). Öğrenme güçlüğü olan ve olmayan çocuklarda akıcı okuma ve okuduğunu anlama becerileri arasındaki ilişkinin incelenmesi. Yayımlanmamış yüksek lisans tezi. Ankara: Ankara Üniversitesi.

18. Tutuk, T. (2017). İşitme yetersizliği olan öğrencilere kaynaştırma ortamlarında uygulanan akıcı okuma çalışmalarına yönelik öğretmen görüşlerinin incelenmesi. Yayımlanmamış yüksek lisans tezi. Eskişehir: Eskişehir Osmangazi Üniversitesi.

19. Paris, H. (2017). Ilkokul öğrencilerinin akıı okuma becerilerinin çeşitli değişkenlere göre incelenmesi. Yayımlanmamış yüksek lisans tezi. Kayseri: Erciyes Üniversitesi.

20. Akbey, G.Ö. (2016). Down Sendromlu Bireylerin Akıcı okuma ve okuduğunu anlama ile fonolojik farkındalık düzeyleri. Yayımlanmamış yüksek lisans tezi. Eskişehir: Anadolu Üniversitesi. 
21. Pircioğlu, A. (2016). Ölçünlü Türkiye Türkçesini okulda öğrenen çocukların okuma yanlışlarını düzeltemede ve onları akıcı okumaya ulaştırmada tekrarlı okuma yaklaşımının etkisi. Yayımlanmamış yüksek lisans tezi. Rize: Recep Tayyip Erdoğan Üniversitesi.

22. Gürbüz, A. (2015). Altı dakika yönteminin akıcı okumaya etkisi. Yayımlanmamış yüksek lisans tezi. Uşak: Uşak Üniversitesi.

23. Bilge, H. (2015). Ortaokul öğrencilerinin akıcı okuma becerilerinin çeşitli değiş̧kenlere göre karşılaştırılması. Yayımlanmamış yüksek lisans tezi. Erzincan: Erzincan Üniversitesi.

24. Ilhan, C. (2014). SQ3R akıcI okuma stratejisinin ilkokul 4. sınıf ögrrencilerinin fen ve teknoloji dersi akademik başarıları, problem çözme becerileri ve fen tutumlarına etkisi. Yayımlanmamış yüksek lisans tezi. Kırşehir: Ahi Evran Üniversitesi.

25. Keskin, H.K. (2012). Akıcı okuma yöntemlerinin okuma becerileri üzerindeki etkisi. Yayımlanmamış doktora tezi. Ankara: Gazi Üniversitesi.

26. Baştuğ, M. (2012). ilköğretim I. kademe öğrencilerinin akıcı okuma becerilerinin çeşitli değişkenler açısından incelenmesi. Yayımlanmamış doktora tezi. Ankara: Gazi Üniversitesi.

27. Kaman, Ş. (2012). Akıcı okuma stratejilerini kullanmanın ilköğretim ü̧̧üncü sınıf öğrencilerinde okuma becerisini geliştirmeye etkisi. Yayımlanmamış yüksek lisans tezi. Kırşehir: Ahi Evran Üniversitesi.

28. Ceyhan, S. (2019). Etkileşimli sesli okumanın öğrencilerin okuduğunu anlama, okuma motivasyonu ve akıcı okumalarına etkisi. Yayımlanmamış doktora tezi. Ankara: Gazi Üniversitesi.

29. Bilge, H. (2019). Okuma, yazma ve konuşmada akıcılık ile okuduğunu anlama ve kelime hazinesi arasındaki ilişki. Yayımlanmamış doktora tezi. Ankara: Gazi Üniversitesi.

30. Yazıcı, T. (2019). Yankılı okuma (eko okuma) stratejisinin kullanımının ilkokul üçüncü sınıf öğrencilerinin okuma düzeyini geliştirmeye etkisi. Yayımlanmamış yüksek lisans tezi. İstanbul: İstanbul Aydın Üniversitesi.

31. Güngör, H. (2019). Türkçenin yabancı dil olarak öğretiminde akıcı okuma: durum çalışması. Yayımlanmamış doktora tezi. Bolu: Bolu Abant İzzet Baysal Üniversitesi.

32. Altınok, Ş. (2018). Türk dili ve edebiyatı eğitiminde prozodik kazanımların değerlendirilmesi. Yayımlanmamış doktora tezi. Ankara: Gazi Üniversitesi.

33. Çetin, D. (2013). Bilgisayar destekli prozodi eğitiminin vurgu, ton ve duyguyu algılama ve yansıtma becerilerine etkisi. Yayımlanmamış doktora tezi. Ankara: Gazi Üniversitesi.

34. Sürgen, D. (2019). Öğrenme güçlügü olan ve olmayan öğrencilerin fonolojik farkındalık, hızlıotomatik isimlendirme ve çalışma belleği performanslarının incelenmesi. Yayımlanmamış yüksek lisans tezi. İstanbul: İstanbul Üniversitesi.

35. Yücel, D. (2009). Sesbilgisel farkındalık (Fonolojik farkındalık) eğitiminin okuma sorunu olan çocuklar üzerindeki etkisinin incelenmesi. Yayımlanmamış yüksek lisans tezi. Ankara: Hacettepe Üniversitesi.

36. Erdoğan, Ö. (2009). Illköğretim birinci sınıf öğrencilerinin fonolojik farkındalık becerileri ile okuma ve yazma becerileri arasındaki ilişki. Yayımlanmamış yüksek lisans tezi. Ankara: Hacettepe Üniversitesi.

37. Süel, E.E. (2011). Illköğretim 1. sınıf üstün ve normal zekâ düzeyindeki öğrencilerin fonolojik farkındalık düzeylerinin okuma başarıları üzerine etkisinin karşılaştırılması. Yayımlanmamış yüksek lisans tezi. İstanbul: İstanbul Üniversitesi.

38. Kazanoğlu, D. (2017). Türkçe fonolojik farkındalık testi geliştirilmesi, geçerlik, güvenirlik çalışması. Yayımlanmamış yüksek lisans tezi. Eskişehir: Anadolu Üniversitesi.

39. Demirtaş, Ç.P. (2017). Okuma güçlügü olan öğrencilerde okuma, sesbilgisel farkındalık, hızlı isimlendirme ve çalışma belleği becerilerinin incelenmesi. Yayımlanmamış yüksek lisans tezi. Ankara: Ankara Üniversitesi.

40. Soğancı, S. (2017). Sesbilgisel farkındalık becerilerinin sözcük okuma becerisi ile ilişkisinin incelenmesi: boylamsal bir çalışma. Yayımlanmamış yüksek lisans tezi. Ankara: Ankara Üniversitesi.

41. Topalca, S. (2019). Drama yönteminin dislekside sesbilgisel farkındalık becerisine etkisi. Yayımlanmamış yüksek lisans tezi. Ankara: Gazi Üniversitesi. 
42. Külte, Ş.í. (2019). 2-6 yaş arası down sendromlu bireyler ile normal gelişim gösteren bireylerin fonolojik Farkındalık düzeylerinin karşılaştırılması. Yayımlanmamış yüksek lisans tezi. Konya: Necmettin Erbakan Üniversitesi.

43. Şahin, K. (Devam ediyor). Okuma güçlüğü çeken ortaokul öğrencileri üzerine bir eylem araştırması. Yayımlanmamış yüksek lisans tezi. Kırıkkale: Kırıkkale Üniversitesi.

\section{Extended Abstract}

\section{Introduction}

Reading can be defined as acquiring information by assigning meanings to written or printed symbols. In the reading process, voice awareness, voice, word recognition, fluent reading and understanding should be realized. For this reason, fluent reading skills should be acquired at the beginning of reading education. Fluent reading is reading the text as if speaking with appropriate speed, rhythm and articulation. Fluent reading affects articulation, comprehension, reading interest and motivation, and supports reading habits. Fluent reading is based on four basic elements: Word recognition, comprehension, prosody, automaticity (speed). Faultless articulation of the letters and words in the text of the reader is defined as word recognition. Recognition of words in the text while reading, reading and comprehension the text at the appropriate speed are defined as automaticity or reading speed. It was stated that when automaticity and word recognition aren't achieved, syllabication, pausing, turnabouts and falsely read words during reading will hinder forming comprehension units. In order to focus attention on comprehension while reading, students are supposed to have acquired word recognition and automaticity skills, but this is not enough because students are also supposed to have acquired the last constituent of fluent reading skill, which is prosodic reading (Ulu, 2016). Comprehension in fluent reading is an important factor. It is based on drawing conclusions from the text read. Comprehension occurs along with automaticity (speed), prosody, and word recognition. Previously, reading fluency was a study area neglected in reading research. However, in recent years, research on reading fluency has clearly indicated that reading fluency has an important role in the acquisition process of reading proficiency (Yamac \& Celiktürk Zengin).

\section{Method}

In the study, it is aimed to determine the tendencies of graduate theses related to fluent reading. The research was carried out according to the qualitative research method and descriptive content analysis method was used. The data source of the research consists of postgraduate theses on fluent reading in the Council of Higher Education (CHE) National Thesis Center, prepared until the 2020. The data source of the research was created by scanning through the CHE National Thesis Center website. Fluent reading, prosodic reading and phonological awareness were scanned with key concepts. In the study publication classification form was used. The form has been arranged in accordance with the purpose and content of the study. The form consists of seven chapters regarding the data source such as year, university, type, subject, method, sampling, data collection tools, data analysis method. The data were evaluated in accordance with the stages of the content analysis method. Content analysis is based on the coding, classification and definition of the data obtained. In the analysis process, each thesis is classified according to the type, year, university, subject, research method, sample, data collection tools and data analysis methods. In the analysis of the data, firstly, data entry related to the identity (name, author, year of publication, university etc.) of the data source was made. Then the type, subject, method, sample, data collection tools and data analysis methods were determined. However, in some theses, it is seen that there is not enough information about method, data collection tools and analysis methods. Opinions of the field experts on the data were asked and the data were coded in line with the opinions received. The data encoded in SPSS was interpreted using frequency, which is one of the descriptive analysis techniques. 


\section{Result and Discussion}

As a result of the research, it was determined that 43 different theses about fluent reading have been prepared since 2009. It has been observed that a thesis about fluent reading was prepared most in 2019 and these theses were mostly carried out in Gazi University's postgraduate programs. In addition, it was determined that the topic of developing fluent reading skills was preferred in theses on fluent reading. It was also revealed that fluent reading level, the relationship between fluent reading comprehension, reading difficulty, motivation, attitude and phonological awareness are covered. It is determined that quantitative research patterns are applied in the theses on reading fluent reading. In addition, depending on these patterns, it was determined that tools such as scale, test and inventory were used, and quantitative predictive statistics were used. The results of the research were found to be supported by the results of other scientific studies related to reading and the results were discussed (Ceran etc., 2018; Akaydın and Çeçen, 2015 etc.). Based on the conclusions reached, various suggestions are presented for research on fluent reading. In this context, suggestions such as conducting studies on different goals and sampling characteristics from elementary school to secondary education related to fluent reading, determining the problems experienced, determining the competencies of prospective teachers and teachers were presented. 